\title{
ЗНАЧЕНИЕ ПРОГРАММНЫХ ДОКУМЕНТОВ В ПРОЦЕССЕ ФОРМИРОВАНИЯ И СТАНОВЛЕНИЯ ОСНОВНЫХ ПРИНЦИПОВ МЕТОДОЛОГИИ НАУЧНО-ИССЛЕДОВАТЕЛЬСКОЙ ДЕЯТЕЛЬНОСТИ ПЕРВОЙ ЧЕТВЕРТИ ХХ СТОЛЕТИЯ
}

\author{
И. В. Мазур \\ Украина, г. Хмельниикий, Хмельниикая гуманитарно-педагогическая академия
}

DOI: https://doi.org/10.31435/rsglobal_ijitss/31032020/7012

\section{ARTICLE INFO}

Received 14 January 2020

Accepted 18 March 2020

Published 31 March 2020

\section{KEYWORDS}

musical folklore, principles of the methodology of research material, program documents, folklorists, folkloreethnographic collecting activities, folk song heritage, activity.

\begin{abstract}
The article considers the importance of program documents in the process of formation and establishment of the basic principles of the methodology of research activities of the first quarter of the twentieth century. The study of the features of the collection, recording and systematization of folkloreethnographic material in this temporary period made it possible to clarify the features and specifics of collecting activities. Based on the study of the analysis principles of collection, records and studies of folklore and ethnographic material. The main methodological principles have been identified and identified, which the foundation of the region is considered as for further research and development of Ukrainian musical folklore of the first quarter of the XX century.
\end{abstract}

Citation: И. В. Мазур. (2020) Znachenie Programmnyh Dokumentov v Processe Formirovaniya i Stanovleniya Osnovnyh Principov Metodologii Nauchno-Issledovatel'skoj Deyatel'nosti Pervoj Chetverti XX Stoletiya. International Journal of Innovative Technologies in Social Science. 3(24). doi: 10.31435/rsglobal_ijitss/31032020/7012

Copyright: (C) 2020 И. В. Мазур. This is an open-access article distributed under the terms of the Creative Commons Attribution License (CC BY). The use, distribution or reproduction in other forums is permitted, provided the original author(s) or licensor are credited and that the original publication in this journal is cited, in accordance with accepted academic practice. No use, distribution or reproduction is permitted which does not comply with these terms.

Актуальность. В современном мире, в условиях глобализации и научно-технического прогресса, при наличии инновационных подходов и экспериментальных разработок во многих областях науки и техники, проблема духовного возрождения становится одной из актуальных не только на государственном, но и на мировом уровне. Обогащение современного социокультурного пространства культурным наследием прошлого, является приоритетным заданием, которое стоит перед украинской нацией на сегодняшний день. В процессах формотворчества национального самосознания, признания самобытности и уникальности украинцев определяющую роль играет духовное наследие прошлого, которое зафиксировано и полноценно представлено в разнообразных образцах фольклорного искусства. Формирование основных мировоззренческих принципов украинской нации невозможно без глубокого и детального изучения, осмысления и осознания морально-этических и духовных ценностей, которые должны стать основными базовыми критериями в процессе закономерной эволюции социума, для достижения и выхода на новый уровень духовности.

$\mathrm{XX}$ столетие вошло в историю мировой культуры как авангардное, динамически активное, противоречивое, наполненное разновекторными стилевыми направлениями и течениями, которые предполагали радикальные изменения и трансформации не только в области тематики, 
содержания и использования новых средств выразительности, но и кардинальным образом меняли мировоззрение человечества в целом. В XX столетии произошло принудительное и жесткое нарушение общепринятых норм и законов. Замена важных и определяющих развитие украинской нации категорий и ценностей, подмена и искажение духовных ориентиров, привело к тотальному преобладанию ложных и лживо-пафосных воззваний, к трафаретным и шаблонным манифестам, что в конечном итоге стало одной из причин деформации психологии, ценностных приоритетов и мировоззренческих позиций украинской нации. Решение данной проблемы стало возможным благодаря возрождению духовного наследия, которое испокон веков сохранялось и передавалось из поколения в поколение.

Глобальные политические и социальные потрясения в обществе в этот исторический период привели к необходимости обретения человечеством определенных устоев нравственного и морально-этического порядка. В данном контексте обращение к фольклорным традициям обрело особую актуальность и ценность. Именно возрождение духовного наследия, сосредоточенное в лучших образцах народного творчества, стало тем определяющим фактором, который позволил украинской нации выйти на новый, более высокий уровень социокультурного развития.

Основной целью статьи является рассмотрение значения, функции и роли программных документов в процессе формирования и становления основных принципов методологии научно-исследовательской деятельности первой четверти ХХ столетия.

Основная часть. Среди большинства вопросов исторического прошлого Украины особое и пристальное внимание в исследовательском пространстве обращено к первой четверти $\mathrm{XX}$ столетия - периоду, для которого определяющим фактором развития стал процесс возрождения национальных ценностей, осознания их важности и значимости как фундаментального устоя на пути к дальнейшим достижениям в области научноисследовательских разработок. Появление в этот исторический период большого количества институтов и учреждений, деятельность которых была направлена на собирание, изучение, систематизацию и популяризацию фольклорного наследия украинского народа, свидетельствовало о приоритетности и весомости данного направления народознания.

Основной проблематикой исследовательских работ и научных трудов первой четверти XX столетия становится разработка основополагающих принципов методологии исследования фольклорного материала, которые должны опираться на базовые положения относительно природы, генезиса и значения народных обрядов и традиций. Взгляд на фольклорное наследие, как на основной документ исторического прошлого, который органично связанный с определенным историческим этапом, являясь его неотъемлемым компонентом, ставило перед исследователями сложную и трудоемкую задачу.

Основной массив фольклорно-этнографического материала первой четверти XX столетия был представлен огромным количеством выборочно собранных и зафиксированных образцов народно-песенного творчества, которые рассматривались в полной изоляции от их значения и функции в календарно-обрядовом цикле. Определенным образом вырванные из контекста бытования, народные песни переставали рассматриваться как носители соответствующих традиций, не учитывалась специфика их функционирования в конкретных условиях территориального бытования. Именно этот проблемный вектор стал определяющим при разработке и появлении огромного количества программных документов, направленных на исследование фольклорного наследия.

Создание вопросников, анкет, инструкций, экспериментальные поиски новых способов записи и фиксации народно-песенного материала способствовали активизации деятельности фольклористов и аматоров-любителей, направленной на собирание, фиксацию, изучение и систематизацию фольклорно-этнографического материала. Это были первые шаги на пути к созданию основных методологических принципов научно-исследовательской деятельности.

Необходимость создания программных документов была связана с решением еще одной, достаточно серьезной проблемы, которая в первой четверти ХХ столетия остро встала перед фольклористами. Это было связано с тем, что на территории Украины фольклорноэтнографический материал собирался и обрабатывался неравномерно, не все районы были равноценно и полностью исследованы и изучены. Рядом с систематичными материалами, которые полноценно презентовали разнообразие фольклорного наследия отдельных регионов, 
встречались одиночные образцы песенных жанров, которые были зафиксированы по самым разным причинам. Эти особенности собирательской деятельности не давали возможность воссоздания целостной картины функционирования народно-песенного творчества в разных регионах, не способствовали выявлению и осмыслению особенностей развития и трансформации фольклорного материала на протяжении длительного исторического периода.

Исследования фольклорных образцов первой четверти XX столетия были связаны с решением следующих задач методологического характера: выяснение настоящего объема песенного наследия в конкретном жанре; изучение природы, определение источника происхождения песни; рассмотрение характера, тенденций и направленности развития, выявление и анализ особенностей трансформации материала; обозначение хронологических границ появления и функционирования песенного образца; выяснение и изучение территории бытования материала; нахождение и уточнение моментов взаимодействия и взаимовлияния между песенным образцом и устной давней традицией, литературным наследием прошлого.

Для решения этих проблемных вопросов возникла необходимость создания документов, основной целью которых было предоставление конкретных указаний относительно специфики и особенностей собирания фольклорного материала. В истории украинской музыкальной фольклористики эти документы известны под разными названиями: руководство, инструкция, анкета, установка, план, воззвание, наставление, вопросник, программа, приглашение, квестионар [3].

Несмотря на достаточно большое количество дефиниций и обозначений, все эти документы имеют непосредственное отношение к собирательской деятельности и были созданы с целью ее активизации и поднятия на более высокий уровень научного исследования народного наследия. Активное использование термина «программа» связано с тем, что данный документ содержит не только указания в отношении записи, фиксации и отбора определенных образцов народно-песенного материала, но и рассматривается как определенный алгоритм изучения фольклорно-этнографического наследия. В соответствии с этим, программный документ начинает выполнять функцию исследовательской матрицы.

Необходимо уточнить, что понятия «руководство», «наставление», «инструкция» активно использовались фольклористами до середины XIX столетия. Начиная с 1860 года активно используется термин «программа», который применяется и в современном исследовательском пространстве музыкальной фольклористики.

Учитывая значимость и важность программных документов в процессе становления научно-исследовательской деятельности первой четверти XX столетия, необходимо дать определение базовому понятию: программа - документ, составленный в форме конкретных вопросов, разработанный и утвержденный структурами ВУАН (Всеукраинская Академия Наук), в котором указано алгоритм изучения определенного этнографического или фольклорного явления, образца. Программы необходимо рассматривать как аналитический алгоритм, с помощью которого происходит фиксация образцов песенного творчества и разнообразных явлений фольклорно-этнографического наследия украинского народа.

Одним из первых документов, в котором были изложены правила фиксации фольклорно-этнографического материала, является «Инструкция, данная Академией Г.Ф. Миллеру при отправлении в Сибирское путешествие. Наставление о том, на что надлежит обращать внимание при описании народов, в особенности сибирских. О истории народов», изданная Российской Академией наук на немецком языке в 1733 году [13]. Инструкция состоит из 1297 разработок, которые представляют собой развернутые и детальные рекомендации и указания, касающиеся процесса отбора и фиксации фольклорно-этнографического материала.

Одним из первых документов в области сбора и записи фольклорно-этнографического наследия на территории Украины считается программа Ф. Туманского, которая была составлена в первой половине XIX столетия и предназначалась для полного и детального исследования земель Малороссии [8]. Как и большинство разработок в данной области, эта программа учитывала специфику бытования и функционирования фольклорного творчества в разных местах локации. Вопросы, из которых состояла программа, указывали, на какие народные обычаи, традиции и обряды необходимо обратить внимание в первую очередь, какие жанры песенного творчества следует зафиксировать. Отдельным пунктом программы стоял вопрос о нахождении и изучении записей и летописей, в которых дается информация 
фольклорно-этнографического характера, что поможет в реконструкции и воссоздании исторического прошлого украинской культуры.

Особенностью программы Ф. Туманского является специфика подхода исследователя к сбору, фиксации и изучению фольклорно-этнографического наследия, которая предполагает наличие двух этапов: первый этап - непосредственно процесс собирания и записи материала, второй этап связан с критическим осмыслением и систематизацией собранного материала квалифицированным научным специалистом. Именно второй этап будет рассматриваться в дальнейшем как основной и необходимый компонент научно-исследовательской деятельности фольклористов первой четверти XX столетия. В истории музыкальной фольклористики программа Ф. Туманского рассматривается как одна из первых разработок исследовательского характера, в которой даются указания и рекомендации для изучения фольклорноэтнографического наследия украинского народа.

В истории музыкальной фольклористики особое место принадлежит известному фольклористу О. Кольбергу. Разработанные им рекомендации и инструкции, касающиеся сбора и фиксации фольклорно-этнографического материала, стали основополагающими составными в процессе разработки и формирования основных принципов методологии научноисследовательской деятельности ученых и фольклористов первой четверти ХХ столетия [20, 21]. Обозначив основные цели и задачи собирательской деятельности, исследователь уточняет основные методологические задачи, которые конкретизируются в следующих положениях: необходимость и важность сбора и фиксации фольклорно-этнографического наследия, требование обязательной паспортизации всех собранных материалов. О. Кольберг обращает внимание на то, что при сборе песенного творчества следует записывать не только поэтический текст, но и нотный материал. Запись народно-песенного образца должна отображать специфику и особенности произношения, ударения в словах, диалекты и обороты речи, характерные для конкретной местности. Песня должна быть зафиксирована со всеми вариантами, которые на определенный период времени существуют в конкретном регионе, что позволит проследить специфику и направленность развития фольклорного образца, с учетом всех трансформаций и изменений, которые произошли на протяжении определенного исторического периода. Запись народно-песенного образца конкретного региона предполагает рассмотрение его роли, функции и значения в контексте обрядового действия и народных традиций.

Если в рекомендациях О. Кольберга фольклор рассматривается в общем контексте бытования, с учетом особенностей его взаимосвязи с обычаями и традициями конкретной местности, то начиная с 1860-х годов значение и функция программ начинает меняться и детализироваться соответственно выбранной проблематики. С одной стороны, разрабатываются нормативные документы, касающиеся исследования этнографического материала. С другой стороны, создаются программы, которые направлены на сбор, запись, систематизацию и изучение образцов народно-песенного творчества. В конце XIX столетия параллельно с появлением программных документов фольклорно-этнографической направленности, создаются «вопросники», которые имеют локальное значение и применяются для изучения народного наследия отдельно взятой местности.

За исключением отдельных рекомендаций и программных инструкций, тематика преобладающего большинства программных документов второй половины XIX - начала XX столетия была направлена на изучение вопросов, связанных с рассмотрением этнографии и фольклористики Украины в общем контексте. Основная направленность этих документов заключалась в необходимости создания целостной картины этнографического и фольклорного разнообразия украинского народа. Все первоначальные разработки и инструкции носили общий характер, ни один из вопросов не предполагал конкретику и детализацию.

Если во второй половине XIX столетия основными вопросами и задачами относительно сбора, записи и изучения фольклорно-этнографического наследия активно занимались фольклористы и этнографы Восточной Украины, то в начале XX столетия центр разработок и исследований в этой области перемещается в Галицию (Галичину). Это связано с тем, что при Научном Обществе Шевченка (НОШ) была организована и начала функционировать Этнографическая комиссия, основной целью которой было привлечение к сотрудничеству ученых и фольклористов со всех регионов Украины. Благодаря деятельности М. Грушевского, Ф. Волкова, В. Гнатюка, И. Франка, которые входили в состав комиссии, 
было исследовано и собрано большое количество фольклорно-этнографического материала с разных регионов Украины.

Уровень исследований, которые проводились учеными и сотрудниками НОШ, был показательным для исследователей мирового масштаба, о чем свидетельствовали многочисленные отзывы международных сообществ. Организация и проведение научных конференций, на которых обсуждались разнообразные вопросы, посвященные проблемам сбора, фиксации и изучения фольклорно-этнографического материала, способствовали разработке и определению основных принципов методологии исследования в этой области. В первой четверти XX столетия Научное Общество Шевченка заняло лидирующую позицию среди научных обществ словянских стран по вопросам сбора, записи и систематизации народно-песенного наследия. Песенные сборники, созданные на основе собранных материалов этнографического и фольклорного характера, изданные при содействии Научного Общества, считались образцом и эталоном для многих фольклористов.

В процессе формирования и становления основных принципов методологии научноисследовательской деятельности в области сбора, записи и фиксации фольклорноэтнографического материала важную и определяющую роль сыграла деятельность Российского Географического общества. В 1901 году был разработан и издан «Вопросный лист Песенной Комиссии Императорского Российского Географического общества для сбора песенного материала» [4]. При Обществе ценителей естествознания, антропологии и этнографии была создана специальная Музыкально-этнографическая комиссия, с целью сбора и фиксации «чисто русских народных песен с напевами», сотрудниками которой был разработан и составлен данный программный документ. Впервые в истории музыкальной культуры вопросы сбора и фиксации песенных образцов народного творчества стали объектом изучения и предметом специального исследования. В предисловии к изданию «Песни российского народа», который вышел в двух томах, четко обозначено цель и задание собирательской деятельности [15]. Вопрос «как записывать» рассматривался и считался не менее важным по сравнению с другим вопросом - «что необходимо записывать и фиксировать». Особенностью этих изданий является наличие следующих отличительных признаков: точной фиксации контекста бытования песенных образцов; четко и правильно составленных паспортных данных исполнителей; терминологического словаря, с помощью которого можно выяснить значение слов, которые встречаются в песенных образцах.

Впервые в истории музыкальной фольклористики программа была составлена из вопросов, касающихся записи образцов народного творчества как песенного, так и инструментального происхождения. Особое внимание уделялось сбору и фиксации определенных жанров фольклора: исторических, календарно-обрядовых песен, духовных стихов. При записи образцов народного творчества акцент делался на точной записи особенностей интонирования, характере и манере исполнения, фиксации речевых и диалектических оборотов, функции песни в обрядовом цикле. В программе четко оговаривалось, что запись образца песенного или инструментального творчества обязательно должен сопровождаться комментариями и мнением самого респондента в отношении исполняемого образца.

В 1901-1902 годах Музыкально-этнографической комиссией были разработаны программы, которые детализированы и уточнены относительно материала для собирательской деятельности, например «Программа для собирания народных песен и других музыкально-этнографических материалов» [16]. Поскольку над созданием и разработкой программ работали преимущественно языковеды и филологи, руководитель комиссии обратился к фольклористам с просьбой о внесении необходимых уточнений и обязательной корректировке программных документов.

В начале XX столетия фольклористами и аматорами-любителями было собрано достаточно большое количество разнообразного материала как в этнографическом, так и фольклорном отношении, который требовал систематизации и изучения. Особое внимание уделялось комплексному рассмотрению народного творчества, при изучении которого использовались четко обозначенные принципы исследования, к которым относятся: сбор фольклорно-этнографического материала в конкретных регионах и местностях, фиксация и запись четко обозначенных жанров песенного творчества, паспортизация данных исполнителей.

Собирательская деятельность происходила по определенному алгоритму: на основе программных документов, которые состояли из разнообразных вопросов, проводился опрос и одновременно делалась синхронная запись и фиксация не только этнографических, но и 
песенных материалов. Собирая и записывая образцы народно-песенного творчества, фольклористы и аматоры-любители сталкивались с проблемами филологии и языкознания, которые заключались в невозможности точной и соответствующей произношению записи. Определенные сложности возникали при публикации песенных образцов, которые в определенной мере напоминали скорее схематические наброски основных интонационных моделей жанров фольклора, которые не отображали всю самобытность, оригинальность и индивидуальность образцов народно-песенного наследия. Решение данной проблематики вызывало необходимость тесного сотрудничества фольклористов и аматоров-любителей с филологами, языковедами, лингвистами, историками, музыковедами и т.д.

Наличие большого количества разработок, инструкций, программных документов, появление печатных изданий народно-песенных материалов, научных статей и работ, в которых рассматривались вопросы сбора, записи и изучения фольклорно-этнографического наследия свидетельствуют о формировании в первой четверти XX столетия основных принципов методологии научно-исследовательской деятельности в этой области. Одним из главных принципов собирательской деятельности становится точность и максимально полная фиксация всех особенностей бытования фольклорных образцов. Народная песня начинает изучаться комплексно, рассматривается ее роль и значение в календарно-обрядовом комплексе, учитывается специфика и условия бытования в конкретном регионе. В начале XX столетия в структуре программных документов происходят изменения, которые связаны с появлением предисловия, в котором изложены рекомендации относительно особенностей сбора и фиксации материала.

В статье Е. Кагарова «Задания и методика этнографии» четко обозначены задания собирательской деятельности [12]. С точки зрения исследователя, фольклорно-этнографический материал необходимо систематизировать исходя из специфики его функционирования, особенностей применения и значения. Исследователь предлагает следующую классификацию собранных материалов: непосредственные источники (материальные предметы обихода и домашней утвари) и посредственные источники (дневники, заметки и записи фольклористов, сделанные непосредственно во время экспедиций, информация из рукописей и других архивных документов). В отношении сбора фольклорно-этнографического материала, Е. Кагаров выделяет два способа: лабораторный (специфика заключается в сборе необходимой информации с помощью музейных экспонатов, библиотечных и архивных фондов) и полевой или экспедиционный (сбор и запись материала производится непосредственно от исполнителей в конкретном регионе). В статье акцентируется внимание на ценности и важности программных документов в процессе сбора, записи и изучения фольклорно-этнографического материала, которые позволяют систематизировать собранный материал, выявить и проследить особенности изменений и трансформаций, понять закономерности и векторность развития.

Выводы. Программы первой четверти XX столетия конкретизированы и структурированны, имеют четко выраженный предмет исследования, например, сбор украинских похоронных причитаний, запись народных традиций об опришках, сбор сведений о свадебном обряде и традициях, связанных с ним и т.д. Специфика программных документов этого периода свидетельствует о процессе активизации собирательской и исследовательской деятельности: внимание сосредоточено на фиксации конкретных образцов календарно-обрядовых комплексов, происходит жанровая дифференциация песенного материала, присутствует момент осмысления роли, значения и функции песенного образца в аспекте народных обычаев и традиций, обязательным элементом становится детальная паспортизация всех данных исполнителей, фиксируются варианты песни, что создают возможность проследить особенности развития, специфику изменений и трансформаций как в отдельном регионе, так и в проекции исторического прошлого. Именно эти аспекты станут основными и важными принципами методологии научноисследовательской деятельности украинских исследователей и фольклористов в XX столетии.

Ценность программных документов первой четверти XX столетия заключается в попытке точно, полно и достоверно собрать и зафиксировать разнообразный фольклорно-этнографический материал, выяснить условия и особенности его функционирования и бытования, раскрыть особенности развития, рассмотреть специфику изменений и трансформаций. Первые программы сыграли важную и определяющую роль в процессе активизации собирательской деятельности на территории Украины, явившись научным инструментарием для дальнейших научноисследовательских разработок фольклористов XX столетия. 


\section{ЛИТЕРАТУРА}

1. Березовський І. П. Українська радянська фольклористика. Етапи розвитку і проблематика. Київ: Наукова думка, 1968. 342 с.

2. Білоус В. Етнографічні дослідження на західноукраїнських землях у третій чверті XIX ст. Львів: IH НАН України, 2000. 187 с.

3. Боряк О. О. Матеріали 3 історії народознавства в Україні: каталог етнографічних програм (друга половина XVIII - XX ст.). Українознавство. Київ, 1994. Вип. 28. 121 с.

4. Вопросный лист Песенной Комиссии Императорского Русского Географического общества для сбора песенного материала. Киевская старина. 1901. T. LXXV. № 12. C. 173-175.

5. Гарасим Я. І. Нариси до історії української фольклористики: навч. посіб. Київ: Знання, 2009. 301 с.

6. Гнатюк В. Українська народна словесність (В справі записів українського етнографічного матеріялу). Відень: Союз визволення України, 1916. 48 с.

7. Горленко В. Ф. 3 історії українських етнографічних та російсько-українських етнографічних зв'язків. Київ: Наук. думка, 1964. 248 с.

8. Горленко В. Ф. 3 історії формування наукової методики народознавства (анкета Ф. О. Туманського). Народна творчість та етнографія. 1980. № 4. С. 76-83.

9. Грица С. Й. Українська фольклористика XIX - початку XX століття і музичний фольклор: нарис. Київ; Тернопіль: Астон, 2007. 152 с.

10. Довгалюк I. Перша публікація народних мелодій у Галичині. Етномузика: збірка статей та матеріалів / упоряд. І. Довгалюк. Львів, 2013. Ч. 9. С. 93-101.

11. Записки Юго-Западного Отделения Императорского Географического Общества. Киев, 1874. Т. 1: (за 1873 г.). С. 339-367 + 28 с. нотного додатку.

12. Кагаров С. Завдання та методи етнографії. Етнографічний Вісник. Київ, 1929. Кн. 7. С. 3-44.

13. Миллер В.Ф. Программа для собирания этнографических сведений, составленная при этнографическом отделе императорского общества любителей естествознания, антропологии и этнографии. Москва: Типография Е. Г. Потапова. 1887. 147 с.

14. Новицкий Я. П. Программа для собирания этнографических сведений. Екатеринославские губернские ведомости. 1887. № 28. С. 5.

15. Песни русского народа собранные в губерниях Архангельской и Олонецкой в 1886 году, слова записал Ф.М. Истоминъ, напевы - Г. О. Дютшъ. Издано Императорским Русскимъ Географическимъ Обществомъ на средства Высочайше дарованныя. 1894. 276 с.

16. Программа для собирания народных песен и других музыкально-этнографических материалов / сост. под ред. А. Л. Маслова. Москва: Т-во скоропеч. А. А. Левинсон, 1902. 8 с.; Этнографическое отделение Общества любителей естествознания, антропологи и этнографии. Труды Музыкальноэтнографической комиссии. Вып. I.

17. Программа Юго-западного отдела императорского Русского Географического общества для собирания сведений по этнографии. Печатано по определению общего собрания Юго-Западного отдела императорского Русского Географического общества 4 июня 1873. Киев: Типография М. П. Фрица, 1873.77 с.

18. Пыпин А. Н. История русской этнографии. Санкт-Петербург: тип. М. М. Стасюлевича, 1891. T. III: Этнография малорусская. 425 с.

19. Труды этнографическо-статистической экспедиции в Западно-Русский край, снаряженной Русским географическим обществом. Юго-Западный отдел. Материалы и исследования: в 7 т. / собранные П. П. Чубинским. Санкт-Петербург, 1872. Т. I. С. XII-XIII.

20. Kolberg O. Pokucie. Cz. 4: Dzieła wszystkie. T. 32. Wrocław; Poznań: Polskie Wyd-wo Myzyczne, Ludowa Spółdzielnia Wydcza, 1962.

21. Kolberg O. Przysłowia: Dzieła wszystkie. Z rękopisów opracował i zredagował S. Świrko. Warszawa: Ludowa Spółdzielnia Wydawnicza, 1967.

22. Kolberg O. Pokucie - Suplement do T. 29-32: Dzieła wszystkie. T. 81. Wrocław; Poznań: Polskie Tow-wo Ludoznawce, Instytut im. Oskara Kolberga, 2008. 